chininsäure und Sulfocinchoninsäure bezeichnet; das Barytsalz der ersteren Säure ist nach ihm (bei $100^{\circ}$ getrocknet) $\mathrm{C}_{40} \mathrm{H}_{23} \mathrm{BaN}_{2} \mathrm{SO}_{7}$ (gefunden 27,02 , berechnet $26.99 \mathrm{pC}$. schwefelsaurer Baryt), das der zweiten $\mathrm{C}_{40} \mathrm{H}_{23} \mathrm{BaN}_{2} \mathrm{SO}_{5}$ (gefunden 28,13, berechnet 28,03 pC. schwefelsaurer Baryt). Die in diesen Salzen enthaltenen Säuren lassen sich nach Abscheidung des Baryls millelst Schwefelsäure als feste, unkrystallisirbare, sauer schmeckende, nach allen Verbältnissen in Wasser lösliche, auch in Alkohol lösliche Massen erhalten.

\title{
Ueber Kreatin und Kynurensäure im Hundeharn;
} von Justus von Liebig.

Der Harn von einem Hunde, welcher in Versuchen von Professor Bisch off mehrere Wochen mit Fleisch gefütert worden war, sollte in dem hiesigen Laboratorium auf Harnstoff benutzt werden, und lieferle auch bei einfachem $\mathrm{Ab}$ dampfen eine Masse von krystallisirtem Harnstoff; beim Auflösen desselben in Weingeist blieben etwa 50 bis $60 \mathrm{Grm}$. eines schneeweilsen krystallinischen Pulvers zurück, welches in kochendem Wasser löslich war und beim Ablühlen in schönen glasglänzenden Krystallen krystallisirte. Die Krystalle bestanden aus reinem Kreatin.

Bis jetat ist in dem Harn nur die Gegenwart von Kreatinin angenommen worden, und da der Harn beim Sammeln auf meine Veranlassung mit Kalkmilch versetzt worden war, um die Fäulnifs zu verhüten und um die Phosphorsäure zu entfernen, und etwa sechs Wochen gestanden hatte, so lag die 
Vermuthung nahe, dafs der Gehalt des Harns an Kreatin auf einer Umsetzung und Verwandlung des durch den Kalk abgeschiedenen freien Kreatinins beruhe.

Um hierüber zu einem sicheren Anhaltspunkte zu gelangen, habe ich etwa 2 bis $3 \mathrm{Grm}$. schwefelsaures Kreatinin im Februar mit Kalkmilch vermischt, den Gyps abfiltrirt und die klare Lösung in einem verschlossenen Gefälse stehen gelassen. Im November, also nach 8 Monaten, hatle die Flüssigkeit keine Krystalle abgesetzt, allein nach dem Abdampfen lieferte sie eine reichliche Krystallisation von Kreatin, so dafs über den Grund des Vorkommens des Kreatins in dem oben erwähnten Harn kaum ein Zweifel sein kann.

Ich erhielt in der That aus einem andern Harn von demselben Hunde, welcher mit Kalkmilch versetzt und frisch abgedampft worden war, nur Kreatinin, aber in beiden Fällen bei reiner Fleischfütterung sehr beträchtliche Mengen. Das salzsaure Kreatinin liefert bekanntlich mit Chlorzink keinen Niederschlag von der Peltenk of er'schen Kreatininverbindung; setzt man aber der Mischung beider Salze etwas essigsaures Natron za und dampft ab, so scheidet sich salzsaures Kreatinin-Zinkoxyd leicht und sehr rein ab.

Harn von demselben Hunde, welcher mit Fett allein und mit Fett und wenig Fleisch gefüttert worden war, gab beim Abdampfen, Zusatz von Salzsäure und längerem Stehen eine ziemliche Menge von der früher von mir beschriebenen Kynurensäure. Ich war im Stande, einige Grammen davon zu sammeln, während in dem Harn von reiner Fleischfütlerung nur Spuren sich vorfanden.

$\mathrm{Zu}$ den Eigenschaften dieses Körpers, die ich beschrieben habe, habe ich wenig Neues hinzuzufügen; ich hatte denselben früher nur als ein weifses Pulver erhalten, welches aus kurzen nur unter dem Mikroscope erkennbaren feinen Nadeln bestebt. Wenn ein Brei dieser feinen Nadeln in der Flüssigkeit, 
356 Liebig, über Kreatin und Kynurensäure im Hundeharn.

in der sie durch Salpetersäure aus der alkalischen Lösung ausgefällt worden sind, an einem warmen Orte stehen bleibt, so verliert er seine voluminöse Beschaffenheit und verwandelt sich nach einigen Wochen in vierseitige durchsichtige Nadeln von Glasglanz, welche oft einen halben Zoll lang sind, von gelblicher Farbe; in Alkalien aufgelöst und durch Säuren wieder gefällt, nehmen sie die ursprüngliche Beschaffenheit und Eigenschaften wieder an. Die Kynurensäure ist eine äufserst schwache Säure; ich habe erwähnt, dals das Kalisalz und Kalksalz leicht krystallisiren, eben so das Barytsalz, allein die Salze reagiren sehr alkalisch, und Kohlensäure in die Lösung in Barytwasser eingeleitet, fällt sie vollständig als dicken weifsen Brei aus.

Zwei Analysen, welche mein Assistent Dr. Schindling davon unternahm, lieferten im Mittel :

\begin{tabular}{lr} 
Kohlenstoff & 61,81 \\
Stickstoff & 9,09 \\
Wasserstoff & 4,59 \\
Sauerstoff & 24,51 \\
\cline { 2 - 2 } & $100,00$.
\end{tabular}

Die Kohlenstoffbesiimmungen wichen ab von 61,649 $\mathrm{zu}$ 61,987, der Wasserstoff von 4,738 zu 4,457, der Stickstoff mil Natronkalk bestimmt von 8,769 zu 9,418. Ich hatte leider nicht Substanz genug, um diese Analysen vervielfältigen zu können. Nothdürftig stimmen obige Zahlen mit der Formel $\mathrm{C}_{16} \mathrm{NH}_{7} \mathrm{O}_{5}$.

Beim Erhitzen für sich und mit Kalk liefert die Kynurensäure ein flüchtiges condensirbares $0 \mathrm{el}$ von dem Geruche des Benzonitrils. Durch anhaltendes Kochen mit verdünnter Salpetersäure wird sie nicht merklich verändert. 